\title{
Integration of the GCC Stock Markets
}

\author{
Turki Alshammari ${ }^{1}$ \\ ${ }^{1}$ Finance Dept, Kuwait University, Kuwait \\ Correspondence: Turki Alshammari, Finance Dept, Kuwait University, Kuwait.
}

Received: June 7, 2020

doi:10.5430/rwe.v11n5p24
Accepted: July 27, 2020

Online Published: September 3, 2020

URL: https://doi.org/10.5430/rwe.v11n5p24

\begin{abstract}
This study analyzes the short- and long-term interdependence among the Gulf Cooperation Council (GCC) stock markets, namely, Kuwait, Saudi Arabia, Bahrain, Emirates, and Oman. The study finds a solid long-term relationship among the GCC stock markets and that each market contributes significantly to that relationship. The short-term relationship is also supported through the causality tests as well as through impulse response functions. The analysis reveals the Kuwait stock market to be the most influential during the examined period. Also, a feedback exists between the Saudi and the Emirates stock markets. In order to corroborate the results, an ARDL model is specified and its results confirm the cointegration tests. Overall, the results place doubts against the investment diversification principle.
\end{abstract}

Keywords: GCC, cointegration, impulse response function, causality, variance decomposition, ARDL

JEL: C22, G15, N25

\section{Introduction}

Ever since Johansen (1988) and Johansen and Juselius (1990) introduced their cointegration statistical procedure, a vast number of researches was conducted by financial economists to explore the relationships among international stock markets. Researchers do their best to test if a relationship exists between two non-stationary I (1) stock market returns, such that the residuals of the regression are stationary, which indicates that the two series of stock returns are said to be cointegrated. See, for example, Graham et al (2012), Kishor and Singh (2017), Lahrech and Sylwester (2011), Le Kakinaka (2010), Phylaktis, and Ravazzolo (2005), to name a few.

Gulf Cooperation Council (GCC) stock markets are characterized by a solid returns' performance over the last 40 years. GCC stock market authorities have gone far in developing their stock markets by increasing the foreign investment openness, corporate governance, trading transparency, liquidity creation mechanisms, and informational efficiency. GCC governments have become more conscious of the importance of diversifying their economies so as to diversify the source of income instead of depending on oil as a sole source of income. Hence, GCC governments recently have made noticeable domestic and political reforms, reduced their interference in the economy, created flexible monetary policies, and, most importantly, increased their coordination in all the developmental issues in order to strengthen their financial markets so as to attract foreign investors and increase the base and depth of their capital markets. Recent reports confirm that the developmental processes are on the right track as GCC counties have stepped up efforts to better regulate their stock markets through introducing new capital market laws and regulations; thus, enhancing corporate governance and easing restrictions on foreign investors (IMF periodic report, 2019).

Recently, a big bulk of the "Petro-dollar" money has headed back to the GCC stock markets for the reasons mentioned above as well as for the following reasons. Many of the international stock markets have suffered a plunge due to many reasons, the most important of which relate to the overheated technology sectors. Also, the substantial reduction of interest rates to kick start foreign economies after the 2008 financial crises caused several local investment portfolios to turn back to GCC economies. Moreover, the heated scene of the political aspects in western countries has led many investors to bring back their investments where they belong. Furthermore, the increased oil prices in the last eight years have convinced the GCC governments to embark on ambitious reform programs in order to jump-start several previously ignored sectors of their economies.

On the stock markets level, all GCC governments have established independent capital markets authorities in order to wipe out problems related to poor governance, the dearth of transparency, and alleged insider trading. Besides, many tradable investment instruments have been added while others are being worked out for being added. All of 
these efforts have been enriching the GCC stock markets for the last 10 years. Furthermore, all GCC countries have opened the doors for foreign investors to pour part of their investments into the GCC stock markets. Last, but not least, is the introduction of many stock market indices that are analogous to those that exist internationally. Through all of these developmental efforts, the GCC capital market authorities hope to upgrade the current level of their stock markets from "frontier" markets to "emerging" stock markets. The most prestigious investment advisory, MSCI, has been following the GCC stock markets and has already included Kuwait and the Saudi markets into its global indices of frontier markets.

\subsection{The Motivation of the Study}

All the above-mentioned changes are expected to lay their effects on the degree of integration among the GCC stock markets in a way that makes the integration more pronounced in terms of the number of the cointegrated vectors. Unlike all previous studies that handle the cointegration among international stock markets, this study hypothesizes that the cointegration and the interdependence among the GCC stock markets is nearly unique; hence, a current dataset has to be employed in order to test the study conjecture. On the other hand, no work has been done so far to examine the cointegration among the GCC stock markets, but instead, the few studies that cover the GCC stock markets investigate the relationship between these markets along with some macroeconomic variables, such as oil price and interest rates. This study should unfailingly fill this gap and widen the scope of this line of research by including the highly unresearched GCC stock markets. Also, this study strives to shed light on the most influential stock market in the GCC area in terms of its relation (and its effects) to other GCC stock markets. Therefore, the results of this study should be very valuable to international investors.

\section{Literature Review}

The cointegration financial literature is full of studies that deal with the interdependence among stock markets (e.g. Lahrech and Sylwester (2011), Le Kakinaka (2010), Phylaktis, and Ravazzolo (2005)). Recently, Kishor et al (2017) investigated the linkage among the BRIC stock markets (i.e., Brazil, Russia, India, China, and South Africa), along with the Nifty index. The cointegration, along with the causal relationships among these markets is documented, except for the Nifty index. Mohanty et al (2017) investigate the inter-linkages among several stock markets, including India, Korea, and the NYSE. They document cointegration among these markets and also find persistent direct and indirect short-term casual relationships. Many other studies have focused on the GCC stock markets but aimed to uncover the long-term relationship between these stock markets as well as some macro variables, such as the exchange rate, oil price, and interest rates. Hammoudeh et al (2006) examine the relationship between the GCC stock indices and the oil price, the US interest rates, and the US SP500 index. They document a long relationship of GCC markets with the US T-bill rate, but the predictability power of these markets is weak. Maghyereh (2006) examines the interdependence among four MENA stock markets (Jordan, Morocco, Egypt, and Turkey) and documents a weak cointegration among these MENA markets due to the weak economic and financial ties among the related MENA countries. Tripathi et al (2010) investigate the integration of the Indian stock market with Japan, England, the US, and Chinese stock markets. They find the Indian market to be integrated with only the US market but not with other regional markets. Akoum et al (2012) examine the short- and long-term relationship between the oil price and the GCC stock markets as well as in Egypt and Jordan by employing the wavelet coherency methodology. They document weak dependencies among the GCC stock markets, but the long-term relationship with oil price is changing over time. Studies that employ older data sets tend to show weak or no cointegration among global financial markets (see Phylaktis et al 2005, Chen et al (2000).

Although the literature is full of studies about the stock market cointegration, this study differs from the literature in two aspects. The first is that, unlike all previous studies that examined the cointegration of the GCC stock market indices with some macro variables, such as oil price and interest rates, this is the only study that relates to the issue of interdependence among the GCC frontier stock markets that have been striving to switch to the level of emerging markets. Second, this study conjectures that, unlike all the studies in the literature, the close political and economic ties among the GCC countries should be reflected in the cointegration level and intensity by revealing more than two or three cointegrating vectors, as opposed to all previous studies that covered international or regional stock markets that document only one cointegrating vector. This should make the results relatively unique.

\section{Data Analysis}

The data set for this study is the official daily market index levels of the Saudi stock market (Saudi Arabia), the Kuwait tock Exchange (Kuwait), the Bahrain Stock Exchange (Bahrain), the Muscat Stock Market (Oman), and the Dubai Financial Market (UAE). The data set is obtained from Bloomberg database and covers the period from January 2015 to November 2019. This study aims to investigate the inter-linkage, interdependence, and dynamic 
relationship among these five selected markets. Table 1 shows some summary statistics of the data set. Kuwait's stock market is the oldest market while Dubai is the newest market. The largest capitalized market is the Saudi market, with nearly a two million USD market capitalization (as of the end of April 2020), followed by the Kuwait stock market.

Table 1. Summary statistics of the GCC stock market data (Mkt Cap as of April 2020)

\begin{tabular}{lccccc}
\hline & Kuwait & Saudi & Bahrain & Emirates & Oman \\
\hline Year Established & 1977 & 1984 & 1987 & 2000 & 1988 \\
Shares Listed & 204 & 200 & 50 & 66 & 162 \\
Market Cap (Mn USD) & 96,269 & $1,978,740$ & 15,701 & 73,985 & 25,596 \\
Daily Mean Returns & 0.00009 & -0.00004 & -0.00005 & -0.00021 & -0.00046 \\
Daily Median Returns & 0.00025 & 0.0003 & -0.00015 & -0.00032 & -0.00044 \\
SD (Returns) & 0.0057 & 0.011 & 0.0044 & 0.011 & 0.0051
\end{tabular}

$\underline{50-D a y ~ R o l l i n g ~ C o r r e l a t i o n s ~ w i t h ~ K u ~}$

\begin{tabular}{lcccc} 
& Ku-Oman & Ku-KSA & Ku-Dubai & Ku-Bah \\
Mean & $16.42 \%$ & $23.69 \%$ & $24.23 \%$ & $23.31 \%$ \\
SD & $25.89 \%$ & $21.49 \%$ & $22.37 \%$ & $21.11 \%$ \\
Range & 1.14 & 1.10 & 1.11 & 1.08 \\
\hline
\end{tabular}

The mean return of all GCC stock markets during the studied period is negative except for the Kuwait stock market. Table 1 shows that the most volatile markets (the investment risk) are the Saudi and the Dubai stock markets, while the least volatile are the Kuwait and Oman stock markets. Table 1 also shows the time-varying 50-day rolling correlations between GCC stock markets and the Kuwait stock market (as a target market). The latest daily return observation is added while the earliest daily return observation is eliminated. Interestingly, the correlation coefficients are very close to each other (about $24 \%$, except for the Ku with Oman stock market, which is almost $16.5 \%$ ). The volatility of the rolling correlations is also almost the same (about $22 \%$ in terms of the standard deviations). The range values (between the maximum and the minimum values of the correlations) are also very comparable, which implies that the GCC stock market changes are very analogous and parallel with each other. This contradicts what Solnik et al (1996) document that the correlation among global stock markets tends to be quiet volatile and differs with time.

\section{Methodology and Empirical Results}

In order to examine the relationship between the regional GCC stock markets, the following cointegration model is evaluated (following the multivariate test for cointegration advocated by Johansen (1988) and Johansen and Juselious (1990):

$$
Y_{t}=\phi_{t} Y_{t-1}+\phi_{2} Y_{t-2}+\cdots+\phi_{k} Y_{t-k}+\mu+\eta
$$

Where $Y_{t}$ is a $\mathrm{k} 1$ vector of our variables (i.e., Ku is the Kuwait stock market, KSA is the Saudi stock market, Bah is the Bahrain stock market, Dubai is the Emirates stock market, and Oman is the Oman stock market). All data are transformed into stock returns by taking the percentage difference in the stock index value. The test advocated by Johansen is used to test cointegrating relationships between GCC stock markets. The two forms of the test are trace and eigenvalue tests, where trace tests evaluate the number of linear combinations in a country's stock returns while maximum eigenvalue tests connect the cointegration to the stationarity of the return series.

\subsection{Unit Root Tests}

As a prerequisite for the cointegration test, the order of integration (and a unit root test for stationarity) must be carried out so as to avoid the spurious regression problem. Both the Augmented Dickey-Fuller (ADF) and the Phillips-Perron (PP) tests are performed. The PP test is non-parametric; hence, it does not need to specify the form of serial correlation of the dependent variable, and it also considers the autocorrelation and heteroskedasticity issues. Table 2 shows the results. 
Table 2. Unit Root Tests of the GCC stock return series

\begin{tabular}{ccccccc}
\hline & & Bah & KU & KSA & Dubai & Oman \\
\hline ADF & & -20.58 & -19.84 & -29.40 & -32.01 & -25.39 \\
Test & Level & $(0.0001)$ & $(0.0001)$ & $(0.0001)$ & $(0.0001)$ & $(0.0001)$ \\
& & -15.69 & -19.96 & -16.32 & -19.02 & -21.56 \\
& \multirow{2}{*}{$1^{\text {st }}$ Difference } & $(0.0001)$ & $(0.0001)$ & $(0.0001)$ & $(0.0001)$ & $(0.0001)$ \\
& & & & & & \\
PPT & & -30.41 & -29.82 & -29.51 & -32.28 & -25.87 \\
Test & Level & $(0.0001)$ & $(0.0001)$ & $(0.0001)$ & $(0.0001)$ & $(0.0001)$ \\
& & -454.37 & -279.05 & -341.94 & -327.35 & -294.71 \\
& \multirow{2}{*}{$1^{\text {st }}$ Difference } & $(0.0001)$ & $(0.0001)$ & $(0.0001)$ & $(0.0001)$ & $(0.0001)$ \\
\hline
\end{tabular}

The results consider only the return levels and $1^{\text {st }}$ difference, including (a) an intercept, (b) a trend and intercept, (c) and none. The test equation yields similar results; hence, these are not reported to save space. Ku stands for Kuwait, KSA stands for Saudi Arabia, Bah stands for Bahrain, Dubai refers to Emirates, and Oman refers to Oman.

Given the highly significant parameters (p-values between parentheses) for all GCC stock market return series, the null hypothesis of the existence of unit root is rejected at the $1 \%$ significance level, which shows that all the stock return series are stationary. Therefore, all the regional stock returns series are integrated of order $(0)$.

\subsection{Cointegration Tests and VECM Model}

Since the return series are integrated of order (0), the number of cointegrating vectors (relationships) is examined by employing two different likelihood ratio tests, the trace test and the maximum eigenvalue test (i.e., the maximum likelihood-based $\lambda$-max and $\lambda$-trace statistics) as developed by Johansen and Juselius (1990). The test requires that in the set of the five GCC return series, there are $(\mathrm{t}-\mathrm{m})$ common stochastic trends if there are " $\mathrm{r}$ " cointegrating vectors. The likelihood ratio (LR) test is performed so as to determine the optimum lag length of the vector autoregression system (VAR). Considering the AIC criterion, the empirical lag order length is found to be 2 (the results are not reported to save space). Table 3 reports the $\lambda$-max and $\lambda$-trace statistics. Both tests confirm the cointegration among the GCC stock markets at the $1 \%$ significance level, given the high significant values of both the $\lambda$-max and $\lambda$-trace statistics as being higher than their critical values. Moreover, remarkably, the number of significant cointegrating vectors is 5 , which confirms the main conjecture of this study. The most comparable studies in the literature document almost only one cointegrating vector while very few report two cointegrating vectors.

Table 3. Testing the number of cointegrating vectors

\begin{tabular}{ccccccccc}
\hline & \multicolumn{3}{c}{ Hypothesis } & \multicolumn{4}{c}{ Hypothesis } & \multicolumn{2}{c}{ Critical Value } \\
Eigenvalue & Ho & H1 & $\lambda-$ Max & Ho & H1 & $\lambda$ - Trace & $\lambda$ - Max & $\lambda$ - Trace \\
\hline $26.79 \%$ & $\mathrm{r}=0$ & $\mathrm{r}=1$ & $291.3^{*}$ & $\mathrm{r}=0$ & $\mathrm{r}>0$ & $1194.4^{*}$ & 33.9 & 69.8 \\
$25.15 \%$ & $\mathrm{r}=1$ & $\mathrm{r}=2$ & $270.6^{*}$ & $\mathrm{r} \leq 1$ & $\mathrm{r}>1$ & $903.1^{*}$ & 27.6 & 47.9 \\
$22.33 \%$ & $\mathrm{r}=2$ & $\mathrm{r}=3$ & $235.9^{*}$ & $\mathrm{r} \leq 2$ & $\mathrm{r}>2$ & $632.5^{*}$ & 21.1 & 29.8 \\
$20.67 \%$ & $\mathrm{r}=3$ & $\mathrm{r}=4$ & $216.3^{*}$ & $\mathrm{r} \leq 3$ & $\mathrm{r}>3$ & $396.6^{*}$ & 14.3 & 15.5 \\
$17.55 \%$ & $\mathrm{r}=4$ & $\mathrm{r}=5$ & $180.2^{*}$ & $\mathrm{r} \leq 4$ & $\mathrm{r}>4$ & $180.2^{*}$ & 3.8 & 3.8
\end{tabular}

The first normalized eigenvector

$K u=C+0.2 \mathrm{KSA}+0.9 \mathrm{Bah}+0.36$ Dubai +0.05 Oman

The "*" indicates the rejection of the null hypothesis at the $1 \%$ level. The critical values are taken from MacKinnon-Haug-Michelis (1999). " $r$ " represents the number of cointegrating relations.

The conclusion of Table 3 is that there is a long-term relationship among the five GCC stock markets as far as the studied period is concerned, i.e., they move together in the long run. Usually, and according to the results of the 
literature, the number of cointegrating vectors is almost one. It seems that the GCC stock markets are more aligned together for administrative reasons by way of coordinated economic policies. Besides, the vibrant cross-ownership of firms influences cointegration tests. That is, the significant long-term relationship among the GCC stock markets can be explained on the ground of long and strong economic connection, economic and political policy coordination, and the long history of coordinated trade practices (see Cheung et al 1999, and Choudhry 1996).

After normalizing the coefficients of stock returns to one, the restricted long-term relationship among GCC stock returns is calculated (i.e., the cointegrating equation). The first normalized eigenvector (in table 2) indicates that the $\mathrm{Ku}$ stock market (being the target market) is positively related to all other GCC stock markets in the long run (the sign has already been reversed). That is, on average, in the long run, other GCC stock market have a positive impact on the Kuwait market ceteris paribus. The estimated coefficients can be viewed as describing a trend that links the GCC stock returns. For example, a $1 \%$ increase in the Saudi stock market return tends to be associated with a $0.2 \%$ increase in daily Kuwait stock market returns, and so on. One can notice that the largest positive effect comes from the Bahrain stock market.

Of course, the evidence of cointegration among the GCC stock markets implies a violation of the informational market efficiency in the multivariate framework as all GCC stock return series reveal a common stochastic trend; hence, investors need to pay close attention to the portfolio diversification issue as being less effective. On the other hand, cointegration implies significant causality in the returns' system.

The Error Correction Term equation (the ECT or the cointegrating equation) signifies the long-term relationship among the GCC stock markets (Kuwait being the target market). It represents the lagged residuals that are generated from the long-term association among the GCC stock markets. The equation is reproduced from the analysis output as follows:

$$
E C T_{t-1}=1.00 \mathrm{Ku}_{t-1}-0.195 \mathrm{KSA}_{t-1}-0.91 \mathrm{Bah}_{t-1}-0.36 \mathrm{Dubai}_{t-1}-0.05 \mathrm{Oman}_{t-1}-0.0002
$$

The equation above simply indicates the magnitude by which the last period deviation from long-term equilibrium (the error) affects the short-term dynamics of Kuwait stock market returns. Hence, the calculated coefficient precisely measures the speed at which the Kuwait stock market returns to equilibrium after a certain change transpires in other GCC stock market returns. The ECT is calculated to be $69 \%$ (considering four cointegrating vector equations) and it is significant at the $1 \%$ significance level.

\subsection{Causality Tests}

According to Granger (1988) and based upon the cointegration among the GCC stock markets, short-term causal relations among the returns' series can be examined within the framework of the Vector Error Correction Model (VECM). The vector error correction term represents the deviation from the long-term relationship, and its value represents the response of the Kuwait stock market to the departure from equilibrium. The following equation shows the reduced term for the VECM model (Ku is the target market):

$$
E C_{t}=K u_{t}-C+0.2 \mathrm{KSA}_{t}+0.9 \mathrm{Bah}_{t}+0.36 \mathrm{Dubai}_{t}+0.05 \mathrm{Oman}_{t}
$$

Granger (1988) points out that in a VECM, there are two channels of causality: the first is the direct (unidirectional) causality, which is through the error correction term, and the second is through the lagged values of the respective GCC return series (indirect). Table 4 reports the short-term dynamics among the GCC stock markets. The first form of causality shows that the Saudi market significantly affects both the Ku and the Omani markets while it indirectly affects the Bahraini markets through its effect on the Kuwaiti stock market. Also, the Kuwaiti market significantly affects both the Bahraini and the Omani markets, and at the same time, it is significantly influenced by the Emirates stock market. Table 4 also shows one bidirectional causality that runs both ways (a feedback relationship) between the Emirates and the Saudi markets, possibly due to the special political relationship between the two neighbouring counties. Interestingly, the Omani stock market does not influence any of the GCC markets, but it is significantly affected by all other GCC markets (except Bahrain). In general, the causality relations among the GCC stock markets can be explained by the coordinated policies among the GCC countries as well as by the trade and economic agreements implementation. Also, the effects of external shocks usually spread to all GCC markets with daily lags. 
Table 4. Pairwise Granger Causality Tests among GCC stock markets

\begin{tabular}{clllrll}
\hline \multicolumn{3}{c}{ Unidirectional } & \multicolumn{3}{c}{ Bidirectional } & \multicolumn{3}{c}{ Indirect } \\
\cline { 1 - 3 } & $\underline{\text { From }}$ & $\underline{\text { From }}$ & $\underline{\text { To }}$ & $\underline{\text { From }}$ & $\underline{\text { To }}$ & $\underline{\text { Through }}$ \\
$\mathrm{KSA}$ & $\mathrm{Ku}$ & Dubai & KSA & $\mathrm{Ku}$ & Dubai & Bah \\
$\mathrm{KSA}$ & Oman & KSA & Dubai & KSA & Bah & $\mathrm{Ku}$ \\
$\mathrm{Ku}$ & $\mathrm{Bah}$ & & & Dubai & Bah & $\mathrm{Ku}$ \\
$\mathrm{Ku}$ & Oman & & & & & \\
Dubai & $\mathrm{Ku}$ & & & & \\
Dubai & Oman & & & & \\
Bah & Dubai & & & & & \\
\hline
\end{tabular}

The causality is based on a VAR model with four lags. Bah stands for Bahrain, Ku stands for Kuwait, KSA stands for Saudi Arabia, Oman is Oman, and Dubai is Dubai. Observations are 1127 that span the period of 6 January 2015 until 26 November 2019.

\subsection{Variance Decomposition and Impulse Responses}

The above causal findings only give a qualitative description of the relationships among the GCC stock markets. In order to obtain a quantitative measure to these causal relations, the decomposition of variance assists in uncovering how a movement of one market is explained by other markets. That is, the percentage of forecast error variance of the market can be decomposed and employed to measure the precise relation. The orthogonalization is achieved by employing Cholesky decomposition, and the order of the variables corresponds to the order of Ku (target market), KSA, Bah, Dubai, and Oman. Table (5) summarizes the variance decomposition for 1-day, 2-day, 3-day, and 4-day-ahead forecasts in each GCC stock market (as GCC stock markets are strictly regional, the information is expected to flow swiftly over a 4-day ahead forecast horizon).

Table 5. Forecast of error variance of GCC stock markets

\begin{tabular}{|c|c|c|c|c|c|c|}
\hline \multirow[b]{2}{*}{ Market } & & \multicolumn{4}{|c|}{$\%$ of Forecast Error Variance by Innovations in } & \multirow{3}{*}{ Oman } \\
\hline & & $\mathrm{Ku}$ & KSA & Bah & Dubai & \\
\hline Explained & Days & & & & & \\
\hline \multirow[t]{4}{*}{$\mathrm{Ku}$} & 1 & $100.0 \%$ & $0.0 \%$ & $0.0 \%$ & $0.0 \%$ & $0.0 \%$ \\
\hline & 2 & $96.5 \%$ & $1.6 \%$ & $0.7 \%$ & $1.2 \%$ & $0.1 \%$ \\
\hline & 3 & $95.0 \%$ & $1.5 \%$ & $1.4 \%$ & $2.0 \%$ & $0.1 \%$ \\
\hline & 4 & $92.2 \%$ & $2.2 \%$ & $2.7 \%$ & $2.8 \%$ & $0.1 \%$ \\
\hline \multirow[t]{4}{*}{ KSA } & 1 & $12.8 \%$ & $87.2 \%$ & $0.0 \%$ & $0.0 \%$ & $0.0 \%$ \\
\hline & 2 & $16.0 \%$ & $83.6 \%$ & $0.4 \%$ & $0.0 \%$ & $0.0 \%$ \\
\hline & 3 & $16.7 \%$ & $81.5 \%$ & $0.7 \%$ & $1.1 \%$ & $0.1 \%$ \\
\hline & 4 & $18.4 \%$ & $78.7 \%$ & $1.5 \%$ & $1.3 \%$ & $0.1 \%$ \\
\hline \multirow[t]{4}{*}{ Bah } & 1 & $8.9 \%$ & $0.7 \%$ & $90.4 \%$ & $0.0 \%$ & $0.0 \%$ \\
\hline & 2 & $12.0 \%$ & $1.4 \%$ & $86.1 \%$ & $0.5 \%$ & $0.0 \%$ \\
\hline & 3 & $14.7 \%$ & $3.0 \%$ & $81.3 \%$ & $1.1 \%$ & $0.0 \%$ \\
\hline & 4 & $16.1 \%$ & $3.7 \%$ & $78.1 \%$ & $2.0 \%$ & $0.0 \%$ \\
\hline \multirow[t]{2}{*}{ Dubai } & 1 & $15.7 \%$ & $9.9 \%$ & $0.2 \%$ & $74.2 \%$ & $0.0 \%$ \\
\hline & 2 & $18.2 \%$ & $9.1 \%$ & $1.0 \%$ & $71.7 \%$ & $0.0 \%$ \\
\hline
\end{tabular}




$\begin{array}{ccccccc} & 3 & 20.3 \% & 8.0 \% & 1.4 \% & 70.1 \% & 0.3 \% \\ & 4 & 22.6 \% & 7.4 \% & 3.2 \% & 66.6 \% & 0.3 \% \\ \text { Oman } & & & & & \\ & 1 & 7.1 \% & 1.9 \% & 0.2 \% & 3.0 \% & 87.8 \% \\ & 2 & 9.1 \% & 3.4 \% & 0.2 \% & 3.8 \% & 83.6 \% \\ & 3 & 10.6 \% & 2.8 \% & 0.2 \% & 3.8 \% & 82.6 \% \\ & 4 & 10.2 \% & 2.6 \% & 0.1 \% & 3.4 \% & 83.5 \%\end{array}$

Variance decompositions employ Cholesky factors. Ku stands for Kuwait, KSA stands for Saudi Arabia, Oman is Oman, and Dubai is Dubai. The reported numbers indicate the percentage of the forecast error attributed to the innovations at four-time horizons

The results show that in day 1, the highest variance contribution rate of itself is for the Kuwait stock market, as the rate is almost $100 \%$, while the lowest variance contribution rate of itself is for the Emirates stock market as the rate is almost $74 \%$. This finding implies that the Kuwait stock market is the most self-dependent. For example, Kuwait seems to have the most consistent influence on the Dubai stock market as about $23 \%$ of Dubai error variance is explained by the movements in the Kuwait stock market. The results also show that in day 4 (considered relatively a long-run period), the $\mathrm{Ku}$ and Oman stock markets are both strongly exogenous since about $92 \%$ and $84 \%$, respectively, of their error variance is explained by their own shock even after 4 days. The Saudi and Bahrain stock markets are endogenous as their own shocks explain about $78 \%$ of their error variance in 4 days while about $66 \%$ of the error variance of the Emirates stock market returns is explained by its own shocks in 4 days. Furthermore, the results show that the innovations in the Kuwait stock market explain most of the forecast error variance in other GCC stock markets. In other words, the forecast error variance that is explained by the Kuwait stock market to other GCC stock markets ranges from $10.2 \%$ for the Omani stock market to $22.6 \%$ for the Emirates stock market, which indicates that the Kuwait stock market is the most interactive and the most influential in the GCC stock markets. This confirms the findings of the causality tests in Table 3. This is compared to the least influential GCC stock market (the Oman market) as its impact is almost minimal (or even negligible) in terms of the effect of its innovations on the forecast error variance of the other GCC stock markets. If shocks from other GCC stock markets transpire, then the Omani stock market will be the most affected as it is weak and more dependent on its own shocks.

An alternative way to visualize the relationship among GCC stock returns is included in the variance decomposition analysis, and in order to shine some light on the duration of the effect of shocks in one GCC stock market to other GCC markets, the generalized impulse response functions are analyzed. These functions are fetched from the VECM model where one standard deviation shock is considered in each of the four GCC stock markets over a horizon of 4 days. Figure 1 only shows the impulses caused by the Kuwait stock market (being the target market). In general, the impulse response functions appear to be consistent with the results obtained from the VECM and the variance decomposition as discussed above. 


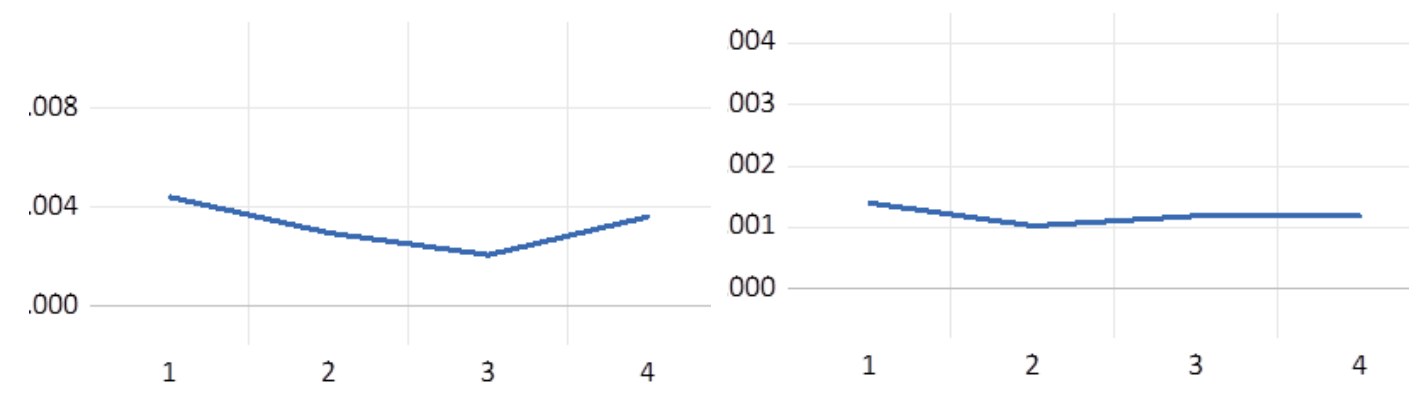

Response of DUBAI to KU Response of OMAN to KU

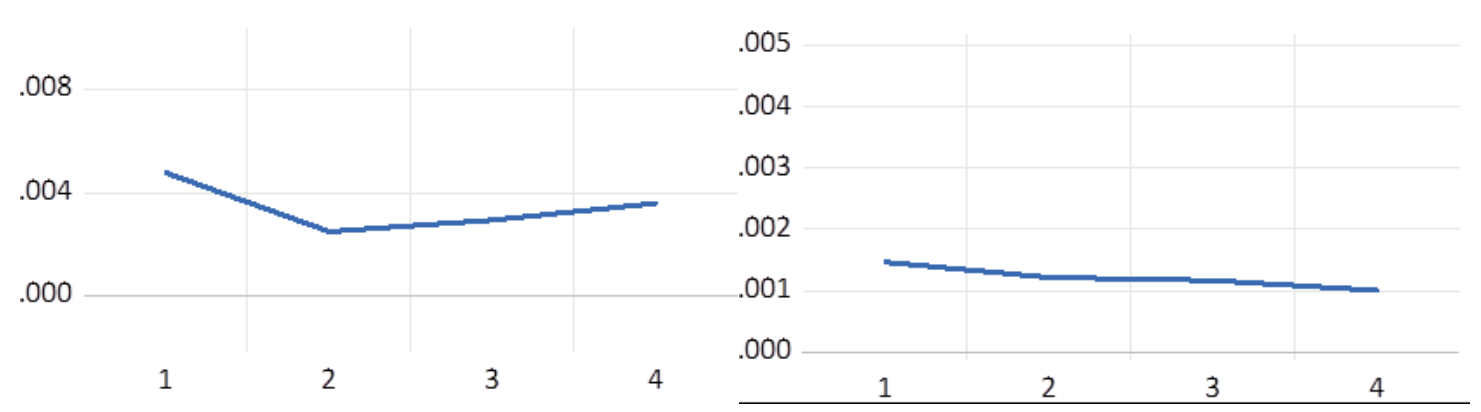

Figure 1. Selected Impulse Response Functions from the VECM Model (Ku is the target market)

Figure 1 shows that the effect of the Kuwait stock market appears to be transitory on Dubai, Saudi, and Bahraini stock markets; however, for the Omani stock market, the effect appears to be permanent as the shock in the Kuwait market shifts the Oman market to a new equilibrium level. That is, the influence of a shock in Kuwait stock market on other GCC stock markets (except Oman) does not die out after 2 days, but instead, brings the system back to its equilibrium level quickly. The impulse responses show a longer effect of the Kuwait market on the Saudi market compared to that on the Dubai and Bahraini markets. The other figures (suppressed for brevity reasons) show almost a trivial effect of shocks of other GCC stock markets on the Kuwait stock market.

\subsection{A Robust Check}

In order to provide a sensitivity check for the cointegration results obtained so far, an alternative statistical procedure (the Autoregressive Distributed Lag Model (ARDL) is carried out. The ARDL procedure provides additional and more integrated parametrization of the data generating process, hence, it provides a good robust check of the Johansen and Juselious (1990) cointegration test results. Since all the prerequisite tests have been carried out, the long-run relationships and short-run dynamic interactions among the GCC stock market returns are empirically analyzed by the ARDL methodology. Table 6 shows the results of carrying out the ARDL as well as the related diagnostic tests. The upper part of the table reports how each stock market is affected by other markets. The numbers in parentheses indicate the short-run dynamic parameters (in the form of daily lags) that illustrate the significant effect (5\% significance level) of the market by other markets. For example, over the short-run, Kuwait's stock market is affected by its own first lagged values by the Saudi market and the Bahraini market on the same day as well as by the fourth lagged day, and so on. It is noticed that by employing the ARDL methodology, the Kuwait stock market appears to be affected by all other GCC markets. This confirms the cointegration results that show Kuwait's stock market as the most interactive market in the GCC countries with respect to its relation to other markets. 
Table 6. The ARDL Bound Test

\begin{tabular}{lccccc}
\hline \multicolumn{5}{c}{ by this market } & (numbers indicate significant lags at the 5\% level) \\
\hline Market Explained & $\mathrm{Ku}$ & $\mathrm{KSA}$ & $\mathrm{Bah}$ & Dubai & Oman \\
$\mathrm{Ku}$ & $(-1)$ & $(0)$ & $(0)(-4)$ & $(0)(-1)$ & $(0)(-1)(-2)$ \\
$\mathrm{KSA}$ & $(0)$ & $(-1)$ & & $(0)$ & \\
Bah & $(0)(-1)(-2)$ & & & & \\
Dubai & $(0)$ & $(0)(-1)(-2)$ & $(-3)(-4)$ & $(-2)$ & $(0)$ \\
Oman & $(0)$ & $(0)(-1)$ & & $(0)(-1)$ & $(-1)$
\end{tabular}

\section{$\underline{\text { Diagnostic }} \quad \underline{\text { Tests }}$}

$\begin{array}{lccccc}\text { Target Market } & \text { Ku } & \text { KSA } & \text { Bah } & \text { Dubai } & \text { Oman } \\ \text { B-G LM (serial Corr.) } & \text { No } & \text { No } & \text { No } & \text { No } & \text { No } \\ \text { CUSUM (Stability) } & \text { stable } & \text { stable } & \text { stable } & \text { stable } & \text { stable } \\ \text { ECT (Speed of adjust) } & -0.880 & -0.868 & -0.089 & -0.957 & -0.78 \\ \text { F-Value (all Coeff=0) } & 115 & 103 & 97 & 119 & 160\end{array}$

$\mathrm{Ku}$ stands for Kuwait, KSA stands for Saudi Arabia, Bah stands for Bahrain, Oman is Oman, and Dubai is Dubai. Observations are 1127 that span the period of 6 January 2015 until 26 November 2019

The lower part of Table 6 includes the related diagnostic and robustness tests. The Breusch-Godfrey Lagrange Multiplier (B-G LM) serial correlation test shows that none of the ARDL models suffer from the serial correlation (according to a high value of the F-statistic). Also, the cumulative sum of recursive residuals (CUSUM) stability test (at 5\% significance level) shows that all ARDL models' parameters appear to be stable (i.e., within the limits); hence, model coefficients do not change during the analyzed period. In order to find out about the long-run horizon association, the error correction term (ECT) of Kuwait (88\%) indicates that the speed of adjustment toward the long-run equilibrium is almost $88 \%$. This means that the whole system (i.e., the best fit of the ARDL model) moves back to the long-run equilibrium at the speed of $88 \%$ in the period under the analysis. The last test is the bound test of cointegration, which yields an F-value of 115 for the Kuwait market model. This value is above both the higher and the lower bounds of Pesaran et al (2001). Hence, the null hypothesis of the equality of coefficients to zero is rejected, which indicates a long-run association between Kuwait and other GCC stock markets.

\section{Conclusion}

This study examines the short-term as well as the long-term relationships in the GCC stock markets, namely, the Kuwait, Saudi, Bahraini, Emirates, and Oman stock markets. Also, the degree of the effect of each stock market on other GCC stock markets is investigated. The almost coordinated developmental structural processes by the GCC exchange commissions has laid its effect on the statistical results in terms of a more concrete relationship over the long-run horizon.

Several results deserve to be noted by using daily stock returns of the five GCC stock markets during the period of 2015 through 2019 in order to emphasize the effects of developments over a more recent period. The most important result is that there is a concrete long-run relationship among the GCC stock markets to the point that the diversification investment principle is jeopardized for GCC investors should they seek to invest regionally. The material GCC economic and political agreements instigated a more pronounced integration, that is, 5 significant cointegrating vectors are observed, where each stock market contributes significantly to the long-run relationship. This is relatively more prominent than what is documented by other previous studies in the literature. The cointegration results are corroborated by the ARDL procedure, which documents the same long-run association among the GCC stock markets.

The study also documents a short-run relationship through the Granger causality procedure. The significant causal relationships are detected from the Saudi stock market to both the Kuwait and Oman stock markets, and also, from the Kuwait stock market to both Bahraini and Oman stock markets. One feedback relationship is found between the 
Saudi stock market and the Emirates stock market. The direction of the causality confirms the results of the integration analysis. The innovation analysis comes to support the causality findings. The variance decomposition analysis concludes that the Kuwait stock market is the most influential in the GCC region as far as the studied period is concerned. Innovations from the error variance of the Kuwait stock market prominently affect the error variance of all other GCC stock markets. This implies cointegrated economies of the GCC countries, which is stipulated by the economic treaties as well as by the social connections among the GCC citizens.

\section{Limitations and Recommendations}

Although this study provides new evidence, it has some limitations that are mainly due to data constraints. For example, high-frequency data for frontier and emerging stock markets do not exist, and if they do, they tend to contain errors. Also, the examined time span does not cover the recent global crisis period, the pandemic Covid-19. This might reduce the scope of the study significantly. The study recommends that further research can be conducted by considering extending the time interval. Also, other data that pertain to other financial markets such as the oil market may be covered.

\section{References}

Akouma, I., Graham, M., Kivihaho, J., Nikkinen, J., \& Omran, M. (2012). Co-movement of Oil Price and Stock Prices in the GCC region: a Wavelet Analysis. The Quarterly Review of Economics and Finance, 52, 385-394.

Chen, G., Firth, M., \& Oliver, M. (2000). Stock Market Linkages: Evidence from Latin America. Journal of Banking \& Finance, 26(6), 1113-1141.

Cheung, Y.-W., \& Lai, K. S. (1999). Macroeconomic determinants of long-term stock market co-movements among major EMS countries. Applied Financial Economics, 9, 73-85.

Choudhry, T. (1996). Interdependence of Stock Markets: Evidence from Europe During the 1920s and the 1930s. Applied Financial Economics, 6, 243-249.

Graham, Kiviaho, \& Nikkinen. (2012). Integration of 22 Emerging Stock Markets: A three-Dimensional Analysis. Global Finance Journal, 23, 34-47.

Hammoudeh, S., \& Choi, K. (2006). Behavior of GCC Stock Markets and Impacts of US oil and Financial Markets. Research in International Business and Finance, 20, 22-44.

Kishor, N., \& Singh, R. (2017). Contagion Effect among the BRICS Stock Market Indices. Journal of Poverty, Investment and Development, 31, 33-46.

Lahrech, S. (2011). U.S. and Latin American Stock Market Linkages. Journal of International Money and Finance, 30, 1341-1357.

Le, K. (2010). International Transmission of Stock Returns: Mean and Volatility Spillover Effects in Indonesia and Malaysia. The International Journal of Business and Finance Research, 4(1).

Maghyereh, A. (2006). Regional Integration of Stock Markets in MENA Countries. Journal of Emerging Market Finance, 5(1), 59-94.

Mohanty, S., \& Priyanka, P. (2017). Interlinkages of Asian and US Stock Market: A Study of selected Indices. Asian Journal of Research in Banking and Finance, 70(10), 1-10.

Phylaktis, K., \& Ravazzolo, F. (2005). Stock Market Linkages in Emerging Markets: Implications for International Portfolio Diversification. Journal of International Financial Markets, Institutions, and Money, 15(2), 91-106.

Solnik, B., Boucrelle, C., \& Y. L. (1996). International Market Correlation and Volatility. Financial Analysts Journal, 52(5), 17-25.

Tripathi, V., \& Sethi, Sh. (2010). Integration of Indian Stock Market with Major Global Stock Markets. Asian Journal of Business and Accounting, 3(1), 117-134.

\section{Copyrights}

Copyright for this article is retained by the author(s), with first publication rights granted to the journal.

This is an open-access article distributed under the terms and conditions of the Creative Commons Attribution license (http://creativecommons.org/licenses/by/4.0/). 